\title{
Amazing Thailand: Organizational Culture in the Thai Public Sector
}

\author{
Nattavud Pimpa \\ Correspondence: Nattavud Pimpa, School of Management, Royal Melbourne Institute of Technology (RMIT \\ University), Melbourne, Australia. E-mail: nattavud.pimpa@rmit.edu.au
}

Received: August 19, 2012

Accepted: August 30, 2012

Online Published: October 16, 2012

doi:10.5539/ibr.v5n11p35

URL: http://dx.doi.org/10.5539/ibr.v5n11p35

\begin{abstract}
Thai culture is unique and renowned for its complexities. To understand the repercussion of culture on Thai management style in the public sector context, this study investigates the key 'characteristics' and 'nature' of culture in the Thai public sector organizations. By adopting Hofstede's theory of cultural dimensions, this study proposes that the new generation in the Thai organizations acts differently from the cultural stereotype from the literature in Thai culture and management. The results show that younger generations in the Thai public sector may be more individualistic, familiar with the concept of organizational change and appreciate the Western management concepts. This study, however, also confirms that avoiding conflict and uncertainties remain a key characteristic in the Thai public sector system.
\end{abstract}

Keywords: organizational culture, Thailand, public sector, management and culture

\section{Introduction}

The effect of culture on organizational management has long been one of the most popular and interesting topics among scholars in international business and management (Kwon, 2011). Previous studies in international business and organizational studies confirm the complexity of culture in the management of all forms of organizations (Johanson \& Vahlne, 2003; Chevrier, 2003; Zahari \& Shurbagi, 2012). A number of studies have been conducted and confirmed strong relationship among various organizational factors and culture (e.g. Swierczek \& Onishi, 2003; Zahari \& Shurbagi, 2012).

Geert Hofstede is one of the prominent researchers in cultural studies who successfully identified the classification of culture and simplify the concept of cross-culture management. His work on culture so far is the most influential study in the field of cross-cultural management (Fang, 2010). In 1980's Hofstede first published the results of his study of more than 100,000 employees of the multinational IBM in 40 countries (Hofstede, 1989). Hofstede was attempting to locate value dimensions across which cultures vary. His theory on cultural dimensions has been widely cited by a number of scholars in international business.

In his concept of cultural dimensions, he describes individualism-collectivism dimension from loosely structured to tightly integrate. The masculinity-femininity dimension describes how a culture's dominant values are assertive or nurturing. Power distance refers to the distribution of influence within a culture. Uncertainty avoidance reflects a culture's tolerance of ambiguity and acceptance of risk. Hofstede $(2001 ; 2004)$ also identified a fifth dimension, a Confucian dynamism labeled long-term orientation versus short-term orientation to life. The Confucian dynamism dimension describes cultures that range from short-term values with respect for tradition and reciprocity in social relations to long-term values with persistence and ordering relationships by status.

Like most popular academic theories, Hofstede's interpretation of culture has received a mountain of criticism. Criticisms on methodology and the attempt to generalize culture according to the country are common. Johanson and Vahlne (2003) pointed that national culture can be defined in different ways. Most definitions, however, state that some kind of meaning or behavior is shared among all members in the group. His study focuses on uncovering differences among IBM employees in different countries worldwide. Thus, Hofstede hypothesizes and defines that each individual is mainly targeted by non-interacting and durable cultures: the national, the corporate and the occupational culture.

He assumed in his IBM research study that every IBM IT-programmer has the same "IT-programmer culture" and is a bearer of the single monopolistic IBM organizational culture - no matter where his workplace is. "The only thing that can account for systematic and consistent differences between national groups within such a 
homogenous multinational population is nationality itself" (Hofstede, 1999).

Researchers in international management (i.e. Lu \& Bemish, 2001; Chevrier, 2003) pointed that the concept of cross-cultural management, such as one from Hofstede, stems from quantitative study based on North American's views to the world. Chevrier (2003) claims that, in such studies, some points on skills and traits frequently associated with successful leaders like flexibility, charisma, honesty, and self-confidence may not be useful in a cross-cultural project involving members from various cultural backgrounds. Chevrier (2003) also adds that:

"most literature about cross-cultural leadership is normative; it is illustrated by a great amount of spicy anecdotes and success stories, but at least to our knowledge, few empirical researches have been made on actual strategies that leaders of multinational teams actually use to manage cross-cultural differences."

Clearly, Hofstede's cultural dimensions ignited the profound intellectual interpretation of culture and the way it affects management, from both protagonist and antagonist's perspectives. Hofstede's concept, however, may lack its validity in the society where subculture is strong, due to race and ethnicity, religion and belief, and geopolitical factor. Some researchers have identified variables such as the proportional representation of the different groups suggesting that relatively equal proportions are required to benefit from the diversity (Chevrier, 2003).

In the Thai context, it is crucial to understand the application of this concept in the contemporary Thai organizations. Key Western management practices such as the development of employee skills, knowledge management, and increasing technical and professional capabilities are common norms in modern Thai public and private organizations. However, less is known about the relationship among the practice of Western organizational culture, traditional Thai national culture and patterns of behavior among Thai workers.

\section{Literature Review}

According to Hofstede's analysis of Thai culture dimensions, Thailand has a low level individualism (and tends to be one of the highest in being collectivistic society). This is manifest in a close long-term commitment to the member 'group', is that a family, extended family, or extended relationships. Loyalty in a collectivist culture is paramount, and over-rides most other societal rules and regulations. The society fosters strong relationships where everyone takes responsibility for fellow members of their group (Hofstede, 1984). Thailand is a collectivist country, where "people from birth onwards are integrated into strong, cohesive in-groups, which throughout people's lifetime continue to protect them in exchange for unquestioning loyalty" (Hofstede, 2001).

One influential concept in the Thai society is "Jong Tum Dee ta Ya Den Ja Pen Pai" (Do the best thing but do not stand out because it will bring harm to you). The Thais believe that doing the right thing according to the group's standard is perfect. However, nobody ever wants to see anyone more outstanding than him/herself. Being outstanding from the group (เด่น) can bring dissatisfaction or bad reputation to you because you can be seen as a threat for the group or your leader. On the positive side, Mulder (1994) proposed that Thai relationship build on personal motivations, based on "Boon Koon" (goodness or usefulness บุญคุณ) and obligation, on the need for affiliation and security, and the more intense these motivations, the more stable and predictable the relationship will be.

One should be loyal to one's parents, relatives, circle of friends and classmates; the further one moves into the realm of outsiders, the less predictable relationship will be (Mulder, 1994). This concept foster the power of group in the society when one perceives him/herself as a member of the group and should do the right thing for the group. The concern for saving face, another personality variable, is an important concept. In the collectivist society, people are concerned about what others think of their actions and try to gain respect by acting in a way that meets the expectations of the individuals around them. Their inability to understand the new system or fear of making inappropriate decisions by using information from a new system may threaten their face because it sends a 'failure' signal to co-workers.

Regarding gender orientation, Thailand has the lowest masculinity ranking among the Asian countries listed at 34, compared to the Asian average of 53 and the World average of 50. This lower level is indicative of a society with less assertiveness and competitiveness, as compared to one where these values are considered more important and significant. This situation also reinforces more traditional male and female roles within the population (Hofstede, 2001). Again, the interpretation of masculinity in the Thai society can be different from those from the West. In Thailand, being a good person means those who can give back to other people and show your care and empathy to everyone. Being genteel is very important to show your respect to other people (อ่อนโยน). It can be interpreted as non-competitive, passive, soft or slow person in the non-Thai context. 
In Hofstede's interpretation (2001), being masculine is being assertive, competitive and possessive. This is not ideal for Thai. Moreover, the old concept of a man is "Chang Tao Na" (the front legs of the elephant, leader) and the woman is "Chang Tao Lung" (the rear legs of the elephant, follower) has been faded away in the modern Thai organization. Like most other societies, gender equity has been emerging as a new concept in Thailand and is well received among the Thais. Thai men are still expected to lead in most circumstances, otherwise they will be perceived as unmanly men (ตุ๊ด).

The high Hofstede Dimension ranking of "Uncertainty Avoidance" in Thailand indicates that Thai society is low in level of tolerance for uncertainty. In an effort to minimize or reduce this level of uncertainty, strict rules, laws, policies, and regulations are adopted and implemented. The ultimate goal of most Thai organizations is to control everything in order to eliminate or avoid the unexpected. As a result of this high Uncertainty Avoidance characteristic, the Thai society rarely accept change and is very risk adverse. In fact, Hofstede's interpretation on uncertainty avoidance is not a foreign concept in Thailand. One of the traditional concepts in Thailand is "Cha Cha Dai Pla Lem Ngam" (Do thing slowly and make sure you get a beautiful big knife). This concept has profound implication on Thai ways of management because Thais tend to make sure that they will not take risk in any activities, if the quality and practices are uncertain.

Hofstede classified Thailand into a large power distance culture in which "superiors and subordinates consider each other as existentially unequal ... [and] subordinates are expected to be told what to do" (2001). According to Hofstede, Thai workers expect to accept 'command' from the boss and tend not to refuse his/her boss. This is because the boss is on the top of management hierarchy. Compared to other societies, Hofstede confirms that the power distance is very significant in the Thai society. Morakul and Wu (2001) found that Thai subordinates accept a hierarchical order and appreciate strong leadership. Liu and Mackinnon (2002) found support that a personality variable, external locus of control due to more powerful others, is related to the power distance dimension. The Thai people, in a high (large) power distance society in which inequality is accepted as a norm, are more likely to ascribe control of events to outside forces, such as more powerful others. This point applies in various settings such as educational institution, business organization and government (Pimpa, 2009).

In the Thai society, the concept of "Ti Tum Ti Soong" is very prominent. Thai tends to believe in Karma and its effect on presence. This is related to their position in family, workplace and society. They are destined to be in the position to accept those who were born in the rich and powerful family. That is destiny and they simply cannot change it. Their position (Ti) is fixed by their familial and social status. The boss represents people at the top of organization or social hierarchy. This is their position and you tend to accept them because of their position, not what they did for the organization. This is simply noticeable in Thailand when people from a handful of influential family tend to have their own spaces in the 'high society'. (ไฮโซ)

Mulders (1994) pointed that Thais deal with power in the social structure in various ways. Symbols of status and power are displayed and Thai people live up to them. Leaders in Thai organizations must realize that to exert or press their position and cause other people feel slighted (Noy Na น้อยใจ) or repressed (Kud Jai ขัดใจ) is loathsome.

For Thais, they perceive the role of leader as a controller rather than a colleague. This may be called 'superior-inferior' concept, which is dominant in Thai organizations (Thanasankit \& Corbitt, 2000). Inferiors in the Thai organizations may be politely and subtly indicated his/her lower position. As long as the atmosphere of friendliness dominates, status and hierarchy will be accepted and appreciated (Mulders, 1994).

Finally, goal orientation which refers to how much society values long-standing-as opposed to short term-tradition values. When Hofstede added this dimension to his theory, he identified long-term orientation society as a place where people place a high value on education, focus on the significance of family and the elder in the family, ordering relationship by status and observing this order, and emphasizes strong work ethic. Thailand scores 56, which is classified as somewhat high long-term orientation. Hofstede attempts to make a link between strong long-term orientation and strong confucious society. Thailand is a Buddhist society with a strong confucious background (Mulders, 1994) where Buddhism deals essentially with virtue and wisdom. The concept of "Morng Karn Klai" (looking ahead) is very common in Thai organization. Children are taught to think ahead about their future and parents believe that education is a form of investment for the long-term prosperity of their children. Most Thai organizations would follow the strong work ethic for the long-term benefits of their organizations. For Thais, staying in one organization for decades is common because it is a sign of long-term commitment and stability of their life. This idea reflects a strong concept of "Morng Karn Klai" in the Thai society.

Previous studies (i.e. Morakul \& Wu, 2001; Swierczek \& Onishi, 2003) adopted Hofstede's cultural dimensions 
to identify the effects of culture in Thai organizations. Almost all of them investigated the influence of the Thai culture on the management of private organizations. Although public sector is among the key systems that drive the country, only a handful of studies can identify the effects of culture on private organizations (Th. As public sector is among the key growing sector in Thailand and has gone through the structural reform, understanding the organizational culture through its perspective is essential for the long-term benefit of Thailand.

\section{Research Methodology}

As identified in the literature, Thai culture is multi-faceted and influential. Organizations in Thailand are influenced by the local culture in various ways. Previous studies identify that culture can influence organizational factors and behaviors such as leadership, communication, decision-making style or strategic thinking (Swierczek \& Onishi, 2003). Due to the gap in the literature on cultural factors and management in Thai public sector, the researcher aims to identify the differences among the Thai public sector staff members, by adopting Hofstede's cultural dimensions to identify the pattern of culture in the Thai public sectors. Alkailani et al. (2012) and Gong et al. (2007) supported that Hofstede's model is still considered the most robust measure of national culture because of its substantial face validity. The researcher, thus, has adopted this model for the current study. The key questions for this paper include:

1. What are the key organizational culture differences among Thai public service officers?

2. What are the implications for the management of modern Thai public sector organizations?

\subsection{Research Approaches}

Quantitative research methodology is adopted as a key approach for this research, due to the nature of research questions. This research aims to investigate and compare differences among groups of Thai public servants regarding their perception on cultural dimensions. Thus, the research aims to quantify the differences among these groups and interpret the effects of cultural dimensions from their perspectives.

\subsection{Participant Characteristics}

The participants of this study are public sector officers under the Thai Ministry of Education. The Ministry of Education is selected because it has a combination of academic and administrative in the nature of work. Furthermore, according to the Thai national budget in 2008, the Ministry of Education was ranked highest in budget and spending. It is also one of the key Ministries according to the National Social and Economic Development plan. Researcher contacted the Ministry of Education and asked for permission to collect the data from schools, vocational colleges and the office of local education in the Northeastern and Central Thailand. Four hundred questionnaires were sent to 20 secondary schools, 10 vocational colleges, and 20 offices of local education. 134 questionnaires were completed and returned to the researcher. Profile of the participants in this study is presented in Table 1.

Table 1. Profile of the participants

\begin{tabular}{l|l}
\hline Sex & Female $=107$, Male $=27$ \\
\hline Level of Education & Undergraduate $=127$, Postgraduate $=7$ \\
Experiences in Public Sector & $4-6 \mathrm{yrs}=5$ Officers \\
& $5-7 \mathrm{yrs}=11$ officers \\
& $10 \mathrm{yrs}$ and longer $=118$ officers \\
Marital Status & Single $=14$, Married $=109, \mathrm{~N} / \mathrm{A}=10$ \\
Organisations & School $=34$ \\
& Vocational College $=35$ \\
& Local Educational Office $=65$ \\
\hline
\end{tabular}

\subsection{Instrument for Data Collection}

The instrument was a questionnaire composed of two parts: the first part related to culture dimensions, based on Hofstede's theory (25 items); while the second part related to participants' demographic information (5 items). The organizational culture was developed from Hofstede's culture dimensions (1984) and various concepts on Thai cultural models from the Thai and non-Thai context.

To verify the inter-item reliability of the instrument, Cronbach's alpha was conducted. In this case alpha coefficients higher than 0.7 , demonstrated the high reliability of the instrument. One of the ways in which to ensure acceptable content validity is to put it through a process of judgmental validation by experts in this area. 
This was done and, in this case, the experts were two academics in international management. They provided feedback that helped the researcher to reiteratively edit the questionnaire.

\subsection{Data Analysis}

In this study, the research adopted some inferential statistical techniques to analyze quantitative data. An independent sample t-test was conducted to compare the cultural dimensions scores for Thai male and female public servants. In the second stage of the analysis, one-way between-groups analysis of variance was conducted to explore the impact of work experiences on cultural dimensions.

\section{Results}

The analyses indicate significant difference in power distance $(t=-2.08, p=.03)$, collectivism $(t=-3.13, p$ $=.01)$, and masculinity $(\mathrm{t}=3.01, \mathrm{p}=.00)$ among Thai male and female public service officers. In terms of power distance, the results show that Thai female public servants tend to accept the power from the leaders within the organization. The analysis also confirms that Thai female are more collectivistic in the organization than Thai male public servants. Not surprisingly, Thai male public servants are more aggressive and assertive than female public servants. Table 2 illustrates the differences among Thai male and female public servants.

Table 2. Sex and Cultural Dimensions

\begin{tabular}{lllll}
\hline Dimensions & Male & Female & t & $\boldsymbol{p}$ \\
\hline Uncertainty Avoidance & 3.90 & 3.78 & .53 & .59 \\
Power Distance & 3.06 & 3.46 & -2.08 & .03 \\
Collectivism & 2.04 & 3.00 & -3.13 & .01 \\
Masculinity & 3.29 & 2.32 & 3.01 & .00 \\
Long-term Goal & 3.73 & 3.68 & .25 & .80 \\
\hline
\end{tabular}

By using level of education to compare their perceptions regarding organizational culture, the results only indicate significant difference among public servants with undergraduate and postgraduate qualifications on masculinity dimension $(\mathrm{t}=-2.91, \mathrm{p}=.04)$. The mean scores indicate that public servant with postgraduate qualifications are more aggressive, task-oriented and try to achieve goals than those with undergraduate qualification (undergraduate $=2.29$, postgraduate $=3.00$ ). Table 3 illustrates the comparison among Thai public servants with undergraduate and postgraduate qualifications.

Table 3. Level of Education and Cultural Dimensions

\begin{tabular}{lllll}
\hline Dimensions & Undergraduate & Postgraduate & t & $\boldsymbol{P}$ \\
\hline Uncertainty Avoidance & 3.81 & 3.73 & .43 & .67 \\
Power Distance & 3.45 & 3.19 & 1.82 & .07 \\
Collectivism & 2.94 & 2.75 & .84 & .41 \\
Masculinity & 2.29 & 3.00 & -2.91 & .04 \\
Long-term Goal & 3.69 & 3.65 & .22 & .82 \\
\hline
\end{tabular}

Finally, a one-way between-groups analysis of variance was conducted to explore the impact of work experiences on cultural dimensions. Subjects were divided into three groups according to their experiences in public sector (Group 1: 4-6 years, Group 2: 7-9 years, Group 3: 10 years and longer). The analyses indicates statistical significance among Thai public servants in levels of collectivism $(F=3.69, p=.02, \eta 2=.02)$ and masculinity $(\mathrm{F}=13.67, \mathrm{p}=.00, \eta 2=.01)$.

Regarding difference among groups, post-hoc comparisons using the Tukey HSD test indicated that, for collectivism, the mean score for public servants who work in the range of 5-9 years $(\mathrm{M}=15, \mathrm{SD}=4.46)$ differ significantly from those who work longer than 10 years $(\mathrm{M}=2.30, \mathrm{SD}=4.55)$.

The analysis on masculinity indicates that the mean scores for public servant who work in the public system for 5 to 9 years $(\mathrm{M}=4.50, \mathrm{SD}=4.22)$ differ significantly from those who stay in the system for 10 years or longer $(\mathrm{M}=2.30, \mathrm{p}=4.32)$. Table 4 illustrates the comparisons among Thai public servants who have different years of service in the public system. 
Table 4. Experiences in Public Sector and Cultural dimensions

\begin{tabular}{|c|c|c|c|c|c|}
\hline Dimensions & 4-6 yrs & 5-9 yrs & 10 yrs and more & $F$ & $p$ \\
\hline Uncertainty Avoidance & 3.81 & 4.10 & 3.78 & .46 & .63 \\
\hline Power Distance & 3.56 & 3.30 & 3.41 & .23 & .79 \\
\hline Collectivism & 2.80 & 2.15 & 2.96 & 3.69 & .02 \\
\hline Masculinity & 2.60 & 4.50 & 2.30 & 13.67 & .00 \\
\hline Long-term Goal & 4.14 & 3.55 & 3.67 & 1.51 & .22 \\
\hline
\end{tabular}

\section{Discussion}

This study reveals a number of points related to the concept of cultural dimensions in the Thai public sector organizations. Of all five dimensions, the results confirm that gender orientation (masculinity) is significant among different groups of public sector officers, based on sex, education and experiences in the public system. Obviously, Thai male public officers with high level of education and some experiences in the public system can be categorized under strong masculine. According to Hofstede, they are more competitive, goal-driven and aggressive than their colleagues. The concept of masculinity can also be interpreted in the sense of gender equity. This study confirms that, among Thai public sector officers, those with higher level of education and have some experiences in the public system are more into gender equity than those with level of education and experiences in the system.

The aspect of collectivism among Thai public sector officers is clearly supported among older generation in this study. This study, however, confirms that the younger generation in the Thai public system is as collectivistic as what reported in Hofstede's work in 1980s. The results from this study reveal that public sector officers tend to be collectivist in their early years and then be more individualistic after spending more time in the public sector system. This can be explained by the nature of Thai public sector organization where new staff needs to rely upon the support of the leader (Tan or ท่าน). In most Thai public sector organizations, the leadership of 'Tan' is very strong among old generation. When one serves in the system for a long period of time and gain a strong status in the organization through the ranking and promotional system, one will become 'Tan' whom everyone, particular new staff, will succumb to his/her power. It can be difficult for young staff to be outstanding and outspoken at the early years without gaining a strong support from 'Tan'.

The concept of power seems to be strong among Thai public officers. This can be inter-linked with the concept of 'Tan' in the Thai organization. Thai female public sector officers seem to accept the power of the boss more easily than their male colleagues. This point confirms that it is not a norm of practice in Thai public sector to challenge their superior (or the power in the organization). Superior who holds power and plays a crucial role in decision-making, strategic planning and implementation will be respected in the organization (Yeganeh \& $\mathrm{Su}$, 2007). When compare power dimension to other four cultural dimensions, it is confirmed that this aspect is still very strong in the Thai organization and will hardly change.

This point is also well-supported by Fang (2010) that in the Hofstede paradigm, Asian organizations are routinely described as collectivistic. Fang (2010) proposed that Asians (including Thai) can be collectivistic thinking and actions may be prioritized and individual identities and initiatives may be dampened and invisible. Similarly, Alkailani et al. (2012) also argued that assumption that people who grow up in the same place will share similar views about life does not apply to the contemporary organization.

It is evident that avoiding conflict and uncertainties will remain a key characteristic in the Thai public sector system. This point may contribute to one characteristic of the Thai public sector organization. They may not like to express their feelings and thinking in the public space, due to the power distance issue in the governmental system. In fact, they may be reluctant to express their ideas and feelings because they do not want to be perceived as those who challenge the leaders. Arguing with superior or colleagues may be seen as trouble-maker of the organization. Perhaps, being quiet and obedient is a sign of good follower in the Thai public system.

In terms of goal orientation, staff members in the Thai public sector system seem to look at the long term prospects of their organizations. The concepts of "Looking ahead" and "Strategic Planning" seem to fit well in the Thai public sector system. Although the analyses do not confirm significant differences among various groups of public sector officers, it is not possible to claim that Thai public sector officers can be strong in goal orientation. With the strong link with building relationship by status in the power distance dimension, this study confirms that Thai public sector officers can build this form of long-term prospects in the organization via the relationship, network and support from those who control power in the organization. Being seen as the follower of the leader who can plan for the future of the organization, Thai staff will agree to have their leaders plan a 
person to be the potential leader for the 'better' future of the organization.

One of the key points from this study is 'change' in the Thai organization is constant. The results from this study confirm some similarities and differences with previous studies in 1980s. This is not uncommon to claim that all aspects of cultural dimension will change with time and situations in the society. In the case of Thailand, key aspects on gender and group orientation have been changing constantly and it is clearly reflected from the attitude of the participants in this study. Some dimensions, however, remain unchanged. This will be an interesting time to observe the current and future of the Thai society because of the local and global changes.

Due to its current political reform, public sector management is one of the key mechanisms for Thailand to move to the next step. Therefore, comprehending cultural values lying within the organization is crucial for the development of the reform. What we see as a stable factor in the Thai society may change with time. The complication of Thai culture is unique and deserves careful attention by researchers and practitioners in organizational management in Thailand.

\section{Acknowledgements}

I would like to acknowledge the support from the Ministry of Education and all Thai participants from different schools and colleges in this study.

\section{References}

Alkailani, M., Azzam, I., \& Athamneh, A. (2012). Replicating Hofstede in Jordan: ungeneralized, re-evaluating the Jordanian culture. International Business Research, 5(4), 71-80. http://dx.doi.org/10.5539/ibr.v5n4p71

Chevrier, S. (2003). Cross-cultural management in multinational project groups. Journal of World Business, 38(2), 141-149. http://dx.doi.org/10.1016/S1090-9516(03)00007-5

Fang, T. (2010). Asian management research needs more self-confidence: reflection on Hofstede (2007) and beyond. Asia Pacific Journal of Management, 27, 155-170. http://dx.doi.org/10.1007/s10490-009-9134-7

Gong, W., Lee, Z., \& Stump, R. (2007). Global internet and access: Cultural considerations. Asia Pacific Journal of Marketing, 19(1), 57-74. http://dx.doi.org/10.1108/13555850710720902

Hofstede, G. ( 2001). Culture's consequences: comparing values, behaviors, institutions and organizations across nations. Sage, Thousand Oaks, CA.

Hofstede, G. (1980). Culture's consequences: international differences in work-related Values. Sage, Beverly Hills, CA.

Hofstede, G. (1984). National cultures revisited. Asia Pacific Journal of Management, 2, 22-28. http://dx.doi.org/10.1007/BF01732507

Hofstede, G. (1989). The universal and the specific in 21st-century global management. Organizational Dynamics, 28(1), 34-43. http://dx.doi.org/10.1016/S0090-2616(00)80005-4

Hofstede, G. (2004). Business goals and corporate governance. Asia Pacific Business Review, 10, 292-301. http://dx.doi.org/10.1080/1360238042000264379

Johanson, J., \& Vahlne, J. (2003). Business relationship learning and commitment in the internationalization process. Journal of International Entrepreneurship, 1, 83-101. http://dx.doi.org/10.1023/A:1023219207042

Kwon, Y. (2011). Relationship specific investments, social capital, and performance: the case of Korean exporter/foreign buyer relations. Asia Pacific Journal of Management, 28(4), 761-773. http://dx.doi.org/10.1007/s10490-009-9172-1

Lu, W., \& Beamish, P. (2001). The internationalization and performance of SMEs. Strategic Management Journal, 22, 565-586. http://dx.doi.org/10.1002/smj.184

Morakul, S., \& Wu, F. (2001). Cultural influence on the ABC implementation in Thailand's environment. Journal of Managerial Psychology, 16(2), 142-58. http://dx.doi.org/10.1108/02683940110380960

Mulder, N. (1994). Inside Thai society: an interpretation of everyday life. Bangkok, Thailand: Duangkamol Press.

Pimpa, N. (2009). Learning problems in transnational business education and training: the case of MBA in Thailand. International journal of Training and Development, 13(4), 262-279. http://dx.doi.org/10.1111/j.1468-2419.2009.00331.x

Swierczek, F., \& Onishi, J. (2003). Culture and conflict: Japanese managers and Thai subordinates. Personnel 
Review, 32(2), 187-210. http://dx.doi.org/10.1108/00483480310460216

Thanasankit, T., \& Corbitt, B. (2000). Cultural context and its impact on requirements elicitation in Thailand. The Electronic Journal of Information Systems in Developing Countries, 1, 1-19.

Yeganeh, H., \& Su, Z. (2007). Comprehending core cultural orientations of Iranian managers. Cross Cultural Management: An International Journal, 14(4), 336-353. http://dx.doi.org/10.1108/13527600710830359

Zahari, I., \& Shurbagi, A. (2012). The effect of organizational culture and the relationship between transformational leadership and job satisfaction in petroleum sector of Libya. International Business Research, 5(9), 89-97. http://dx.doi.org/10.5539/ibr.v5n9p89 